\title{
CAN A LAW OF MORTALITY BE REPRESENTED IN A MATHEMATICAL FORM?
}

\section{To the Editor of the Journal of the Institute of Actuaries.}

SIR, - In submitting for consideration the above question, I venture to express the opinion that it is delusive to imagine, when we have altered a mortality series in accordance with the formulas of $\mathrm{Mr}$ Gompertz or $\mathrm{Mr}$ Makeham, that we are thereby bending our facts into the expression of a law of mortality. I admire the ingenuity with which those formulas have been constructed, and the closeness with which their results approximate to the original facts; but I remain convinced, that the assumption of a law of mortality having been discovered,- - using the word "law" in its scientific sense *, - so as to be expressible in mathematical relations, or, in other words, admitting of quantitative expression, is fallacious. And the following brief observations are offered in justification of this view :-

I. The fact that the laws or uniformities of nature discoverable within the sphere of a physical science can be expressed in a mathematical formula, is evidence that the particular science has attained its final shape,-has, in a word, become exact. Now, the expression of a law of mortality in mathematical language, really implies, though it may not be explicitly stated, that observations of mortality and deductions therefrom have reached the position of a science-and not merely of a science, but of a science in its completed form. It is equivalent to placing mortality deductions on a level, say, with astronomy, or at least of assuming that this is possible to be done. When this real implication of the formulas of Gompertz and Makeham is clearly seen, it will be admitted, I think, that the assumed position is untenable; for no one, so far as I am aware, has ever contended that statistics of the death-rate are entitled to the designation of an exact science.

II. But I go further, and venture to affirm that, from the nature of the data with which we have to deal, the difficulty is really an impossibility. It is only in the purely material sciences that the expression of their laws, or uniformities, in a mathematical shape can be made. In branches of knowledge which involve not merely the outward world, but also human nature, with their inter-actions,- - such as political economy and sociology,-no such attempt is possible: the most distinguished cultivators of those departments-for example, Cairnes, Mill, and Spencer-admit that quantitative expression is unattainable; that, to quote $\mathrm{Mr}$ Cairnes's remark in relation to political economy (The Logical Method of Political Economy), their principles "are not susceptible of arithmetical or mathematical expression." Now, it is clear that mortality belongs to departments of investigation of this latter kind: its factors consist, not simply of

* The word Law is, generally, very inaccurately used, and even cultivated men frequently speak of laws opposing and neutralizing each other. The precise seientific use of the term may be thus illustrated:- In the physical sciences, Gravity is a Force exerted by particles of matter upon each other, whose Lav, or uniform mode of action, is, that it varies directly as the mass and inversely as the square of the distance. Similarly employed in respect of mortality, we should represent Death as a Force operating upon all creatures, and its uniform mode of action (if such a mode could be discovered) as the Law of Mortality. 
outward physical circumstances, but also of principles of human nature, even morality and social habits, the progress even of medical science, the laws of inheritance and evolution, and the like. And, consequently, from the nature of the case, whatever partial uniformities of operation we may discover of the force, death, we cannot express the action in a general mathematical formula.

Not merely, therefore, do I believe that no law of mortality has been discovered which is capable of being exhibited in a mathematical shape, but I also think, from the nature of the subject, that it is futile to expect that such a result will ever be obtained.

In modifying series, accordingly, I am content, in our ignorance, whenever I desire to introduce an element into facts which they do not naturally present, to adopt some distributive process, like the excellent formula of $\mathrm{Mr}$ Woolhouse (which is not the mathematical expression of an assumed mortality law), or the old method of differences. To employ either of the formulas $I$ have referred to, on the ground of being a representation of a law of mortality, which the facts, when altered, are then imagined to reveal, would be, I consider, to assume a non-existent rule, and to make an unjustified interpretation.

It is, I admit, difficult at first to accept this view; for all our terms connected with the alteration of mortality tables involve the preconceived notion that a law exists, and is known: and the association of ideas is consequently strong. For example, the word "adjustment", from its derivation, carries with it the assumption that adjusting a series of numbers is really fitting them into accordance with a law; and the term "graduation", too,--meaning a progression by regular degrees,-involves again the affirmation of a standard or law.

Yours faithfully,

Commercial Union Assurance Co., T. E. YOUNG. Cornhill, London, E.C. Dec. 1879.

\section{DEATH RATES AMONG INFANTS IN SCOTLAND.}

To the Editor of the Journal of the Institute of Actuaries.

Desa Sir,-I have been much interested by Professor Pell's communication in the Journal of the Institute of Actuaries for January 1879, on "The Rates of Mortality in New South Wales", and more especially by the very elear account which be gives at pages 262-5 of the method which he prefers for deducing, by means of registered births and deaths, and without reference to the notoriously incorrect enumerations of persons of each age furnished by census, the probabilities of living for a year at each of the ages $0,1,2,3$, and 4 .

The births and deaths that take place in Scotland are as perfectly registered as those of any country ; and I have accordingly thought it worth while to prepare the accompanying tables, by means of which the numbers and probabilities furnished by recent experience in this country during a series of years may be compared with the similar details for New South Wales which Professor Pell has given. 